\title{
NOVEL DATA SUPPORT MODEL LINKING FLORAL RESOURCES AND HONEY BEE COMPETITION WITH BUMBLE BEE ABUNDANCES IN COASTAL SCRUB
}

\author{
Diane M. Thomson* \\ W.M. Keck Science Department, The Claremont Colleges, 925 N. Mills Avenue, Claremont, CA 91711
}

\begin{abstract}
Growing evidence supports that many bee populations are declining, with potentially serious consequences for pollination services. Mechanistic models that predict bee abundances from drivers like floral resource availability can be a powerful way to understand and address declines, but remain rare and largely unvalidated. I used temporally and spatially novel data to validate previous analyses linking bumble bee (Bombus spp.) declines in California coastal scrub with loss of floral resources, mediated by drought and competition with non-native honey bees (Apis mellifera). New observations from 2015-2018 were combined with data from 1999-2014 to further test these mechanistic hypotheses and evaluate predictions of a statistical model for Bombus abundances. As predicted, positive associations between spring rainfall and floral abundances and between Bombus and key forage plants were consistent between time periods. Increased $A$. mellifera abundance corresponded with reduced Bombus use of the most abundant forage plant and lower Bombus abundances in the following year. Quantitative predictions from the Bombus statistical model previously developed for 1999-2014 were relatively unbiased and strongly rank correlated with either spatially or temporally novel data. However, the model consistently underpredicted Bombus abundances when both flower patch and time period were novel. Overall, four new years of data further strengthen evidence that loss of floral resources due to drought and competition with feral Apis mellifera is an important cause of Bombus decline in this habitat. These findings reinforce the value of even simple models that are mechanistically framed, both in understanding past patterns of change and for qualitative prediction.
\end{abstract}

Keywords: bumble bee, climate, competition, floral resources, honey bee, model validation

\section{INTRODUCTION}

Growing evidence supports that a number of bee populations around the world are declining, raising concerns about effects on pollination services for both crop and wild plants (Powney et al. 2019; Sánchez-Bayo \& Wyckhuys 2019). Numerous potential causes have been hypothesized, including loss of floral resources and nesting habitat, disease and parasites, introduced competitors, pesticides, and climate change (Goulson et al. 2015; Soroye et al. 2020). Most bee habitats are under stress from multiple impacts and their potential interactions, complicating efforts to predict population trends and evaluate conservation strategies.

One important challenge in untangling these multiple effects on bee populations is a lack of predictive models that link environmental conditions such as floral resource availability to population change. Most evidence of declines is indirect, for example decreases in community diversity relative to historic museum collections (Bartomeus et al. 2019). Even where population trends can be documented this may not illuminate the causes, and patterns shown for one time period can change in another (Thomson 2019). The scarcity of research modelling factors that drive variation in bee populations reflects limited availability of abundance and

Received 8 August 202I, accepted I February 202I

*Corresponding author: dthomson@kecksci.claremont.edu demographic data, although a growing number of recent studies has begun to address this gap (Thomson \& Page 2020). Still, relative to the widespread use of models for many other taxa, such approaches are rare for bees.

Over the last decade, a small number of statistical models linking floral resource availability and bee colony or population growth have been developed for both natural and agricultural landscapes (Thomson \& Page 2020). Floral resources in turn may connect with climate changes such as drought frequency (Thomson 2016) or timing of snow melt (Ogilvie et al. 2017), or with habitat characteristics like crop composition and diversity (Hass et al. 2019). The presence of floral resource effects across multiple studies suggests potential strategies to benefit bees, such as wildflower strips. At the same time, spatial and temporal variation in floral resources often correlates with other habitat characteristics like nest site availability or pesticide use. This limitation raises questions about whether floral resources are in fact a primary driver of variation in bee populations, and whether models based on resources can be used to predict population change.

Ecologists broadly agree that both explanatory and predictive models should be evaluated by comparison to independent data (Mouquet et al. 2015; Houlahan et al. 2017; Yates et al. 2018). In practice, validating models this way can be challenging. Data scarcity makes it difficult to withhold observations from model estimation for testing. The most widespread approaches sequentially assign different parts of a data set for test purposes (cross-validation), but do not assess whether models can explain conditions beyond the 
temporal or spatial range of observations used to develop them (Wenger \& Olden 20I2). Statistical methods such as model selection with AIC are a common alternative for evaluating relative model performance. Yet model selection procedures can promote overfitting or misidentify the most important predictors (Houlahan et al. 2017; Clark et al. 2020). Such findings illustrate how gaps in our understanding of underlying mechanisms may be masked by a failure to validate, reinforcing the important of challenging models that inform conservation with novel data.

In this study, I used both spatially and temporally novel data to validate previous analyses of a local decline in bumble bee (Bombus spp.) abundances in coastal California (Thomson 2016). These analyses were originally developed from I2 years of monitoring data (I999-20I4) in I0 patches of flowering central California coastal sage scrub, each patch on the order of several hundred meters in size. Statistical modeling with the 1999-2014 data identified increased competition with non-native, feral honey bees (Apis mellifera) and decreases in key forage plants due to drought as the likely causes of a declining trend in Bombus abundance. I carried out an additional four years of data collection from 2015-2018, including almost all patches used in the original model development and several new ones.

I first used the new (2015-2018) data to reevaluate relationships between precipitation, floral resources, and $A$. mellifera and Bombus competition identified in the 19992014 study (Thomson 2016). Three main patterns from the 1999-20I4 data formed the mechanistic hypotheses: (I) Lower spring rainfall leads to reduced floral resources, but more so for species preferred by Bombus than the community dominant plant most visited by A. mellifera, Eriophyllum staechadifolum; (2) Bombus forage less on E. staechadifolum in years of higher $A$. mellifera abundance due to increased competition, contributing to lower niche overlap; (3) High $A$. mellifera abundance and the associated reduction in niche overlap correspond with lower Bombus abundance in the following year. I assessed whether these relationships were still well supported for the full time series after including the four most recent years (1999-2018). Finally, I tested (4) how well the 1999-2014 fixed effects statistical model for Bombus abundances predicted new data. I compared performance of the Bombus abundance model in predicting three kinds of novel data, observations collected in: (a) I999-20I4 from flower patches not used in the original model selection (spatially novel); (b) 2015-2018 from the original flower patches (temporally novel); and (c) 2015-2018 from all flower patches (both spatially and temporally novel).

\section{MATERIALS AND METHODS}

\section{Study system}

I counted feral Apis mellifera and Bombus foragers from late June to early July in patches of coastal scrub on the central coast of California (Landels-Hill Big Creek Reserve, Lucia, CA, USA, 36 $\left.4^{\circ} 14^{\prime \prime} \mathrm{N}, \quad 121^{\circ} 35^{\prime} 25^{\prime \prime} \mathrm{W}\right)$. This plant community contains a mix of shrubs and mostly perennial herbaceous species. Summer flowering concentrates at lower elevations $(<350 \mathrm{~m})$, where coastal fog buffers temperature and water stress. Visits to four plant species (Eriophyllum staechadifolium [Asteraceae], Scrophularia californica [Scrophulariaceae), Stachys bullata [Lamiaceae], and Phacelia malvifolia [Boraginaceae) encompassed $94.3 \%$ of all $A$. mellifera $(N=27,17 \mathrm{I})$ and $94.7 \%$ of Bombus $(N=6,859)$ foragers counted during this mid-summer period since 1999 . Almost all Bombus were from the $B$. vosnesenskiil $B$. caliginosus color morph, and so could not reliably be identified to species on the wing. I collected B. caliginosus more than B. vosnesenskii (I996-2015: 63.7\%, $N=91$ specimens in color morph), particularly after 2010 (84.6\%, $N=52)$. Bombus californicus ( $N=\mathrm{I} 2$ total observations) and B. melanopygus $(N=4)$ foragers were recorded only rarely.

Monitoring of bee abundances started in 1999 and continued through 2018, except in 200I-2002 and 2008. Not all patches were sampled in every year (Thomson 2016). The new data collection from 2015-2018 included 9 of the I0 patches previously used to model Bombus abundances (Thomson 2016), for on average 2.9 years each (Appendix I, Tab. S2). Monitoring of the tenth original patch stopped in 2007 because of vegetation changes and associated loss of bee forage plants. Distance to the nearest neighbouring patch ranged from 100 to 500 meters for these original patches.

Data collection from 2015-2018 also included 5 patches not used in the earlier analyses (Thomson 2016). Three of these patches were sampled in an average of four years prior to 2015 and 2.7 years in 2015-2018. The original analyses did not include them due to close spatial proximity with another patch (I patch) or because by 2014 fewer than three years of data were available ( 2 patches). These three patches were each within 20 to $35 \mathrm{~m}$ of another patch. I also added two new patches after 2015 ( $N=2$ and $N=3$ years of data). One of these new patches is approximately $150 \mathrm{~m}$ and the second approximately $1000 \mathrm{~m}$ from the next-closest patch.

\section{Weather variables}

I used the same independent variables to characterize yearly weather conditions as in the original analyses (Thomson 2016): total growing season precipitation (Sept. IAug. 3I), days of spring rainfall (March 15 to May I5), and a metric of precipitation timing that helped control for differences in floral and Bombus phenology among years. The precipitation timing (phenology) measure came from multiplying each daily precipitation total from January I to July I by the day in year, then taking the mean. This yielded a mean daily rainfall weighted by day in year, with higher values indicating that more precipitation occurred later in spring. This precipitation timing measure correlated strongly with the ratio between buds and open inflorescences for $E$. staechadifolium, the latest flowering of the major floral resources, from 2009-2014 $(r=0.99)$ (Thomson 2016).

The 8 years prior to 2015 were relatively dry, with 6 experiencing less rainfall than the 1999-2018 annual average (mean \pm one SE: $3 \mathrm{I} .4 \pm 3.7 \mathrm{~cm}$ for 2007-20I4; $39.7 \pm 3.5$ $\mathrm{cm}$ for 1999-2018). In contrast, two of four rain years in 2015-2018 were above the study average, including the wettest year observed since 1999 (Appendix I, Tab. SI). For the other two weather variables, values observed in 2015- 
2018 fell within the range for 1999-20I4 (Appendix I, Tab. SI).

\section{Data collection 2015-2018}

Patches were sampled on 6 to 8 consecutive days each year, between June 29 and July I3. I recorded A. mellifera and Bombus forager numbers with the same methods as in I9992014 (Thomson 2006, 2016). Visual counts were made in each patch by walking a single transect extending $25-100 \mathrm{~m}$ along the edge, looking approximately $5 \mathrm{~m}$ into the vegetation for foraging bees. In every year, I collected data for one observation period per sampled patch during each of three times: morning (9:00-I2:00), midday (I2:00-I5:00), and afternoon (I5:00 to dusk). During each observation period I walked the transect from beginning to end 3 times and recorded all $A$. mellifera and Bombus foragers by plant species, with the starts of these replicate counts 15 minutes apart. This resulted in a total of 9 transect counts per patch for a given year. Air temperature and relative humidity were measured at the beginning and end of every observation period using a sling psychrometer.

I also estimated floral resource abundance with the same methods as in 2009-2014. Flowering stems were recorded for each patch and plant species along the same transect used for bees. I counted stems in $0.2 \mathrm{~m}$ sections of the transect spaced evenly at I $\mathrm{m}$ intervals, looking approximately $5 \mathrm{~m}$ into the patch. Plant species flowering in more than $40 \%$ of these subsamples were recorded at $2 \mathrm{~m}$ rather than I $\mathrm{m}$ intervals. I counted the total number of flowering stems along the whole transect for any visited plant species not found in at least I0\% of subsamples. I also recorded the number of open flowers (or inflorescences for E. staechadifolium) per stem for each species (minimum $N=10$ stems per transect).

\section{Data analysis}

All forager counts and floral abundance data were aggregated by patch and year, so a replicate is the annual mean for one patch (Thomson 2016). I calculated floral density $/ \mathrm{m}$ for each plant species by combining mean stem densities per subsample with the mean number of open flowers per stem. I excluded the 1999-2000 data from floral analyses, because timing of vegetation sampling in those years did not exactly match subsequent monitoring (Thomson 2016). All floral densities were square root transformed to meet assumptions. In 2018, P. malvifolia density in one patch (44) was more than double the next highest value observed in the entire 1999-2018 data set. This difference probably resulted from removal of shrubby vegetation during management of an adjacent road. I therefore removed this single data point (patch/year) from all analyses.

I used general linear mixed models (lme4 version I.I-I9, $R$ version 3.I.4) to evaluate whether the relationship between floral resources and precipitation originally documented for the 1999-20I4 data still held after including the newer 20152018 observations (hypothesis I) (Bates et al. 2015). Flower abundances for three of the four most visited plant species were treated as separate response variables (Scrophularia californica, Stachys bullata, and E. staechadifolium); the fourth species ( $P$. malvifolia) is found in fewer patches and showed no evidence of any relationship with precipitation for either time period. The candidate independent fixed effects included all three weather variables (total growing season precipitation, days of spring rainfall, and precipitation timing), with flower patch as a random effect. I accounted for the time period data were collected (2000-2014 or 20152018) with a categorical fixed effect. Interactions between the precipitation variables and time period were tested to assess how well the original models captured patterns in the new data. A significant time by precipitation term would support that the relationship between floral resources and precipitation differed from 2015-2018 compared to I99920I4, calling the hypothesis about their causal connection into question.

The three floral resource models started with the fixed effects from previously published, best-fit results for each species from I999-2014 (days of spring rain for Scrophularia californica and Stachys bullata, total growing season rainfall and precipitation timing for E. staechadifolium). I then compared alternative models that added or removed candidate variables, including time period by rainfall interactions (Appendix I, Tab. S3; $N=5$ total models for Stachys bullata, $N=6$ each for Scrophularia californica and $E$. staechadifolium). Degrees of freedom and $P$ values were generated with the package lmer.test, using Satterthwhaite's approximation (Kuznetsova et al. 2017; Luke 2017).

I next assessed whether mean $A$. mellifera density still predicted annual niche overlap (hypothesis 2) and Bombus density in the following year (hypothesis 3), as shown in the original 1999-2014 study (Thomson 2016). Niche overlap was quantified as percentage similarity in diet. These analyses used all years of available data (1999-2018), with linear regression for niche overlap and a mixed model with patch random effect for Bombus density. I again included both main and interaction effects of time period to test for differences during 2015-2018. Bombus densities were log transformed to eliminate skew.

The full long-term data set (1999-2018) was also used to evaluate parts of hypotheses 2 and 3 not formally tested in the previously published analyses. I quantified Bombus preference for E. staechadifolium relative to other food sources as the proportion of total Bombus foragers observed on $E$. staechadifolium divided by the fraction of all flowers that were E. staechadifolium. Pearson's correlation analyses were performed for relationships between (a) mean A. mellifera density and Bombus preference for foraging on $E$. staechadifolium, (b) Bombus preference and niche overlap, and (c) niche overlap and Bombus density in the following year. In all cases, I checked plots for evidence of differences in relationships between the 2015-2018 data and earlier years (1999-20I4). If visual inspection showed no interactions with time period, correlation statistics were calculated for all years combined. Bombus preference was square root transformed to eliminate skew.

Finally, I evaluated quantitative predictions of the previously developed fixed effects Bombus abundance model (hypothesis 4): 
Bombus $\sim$ Intercept + Apis $+S_{c a l}+P_{\text {mal }}+$ preciptime + Apis $\times$ Scal

where Bombus is the log-transformed density of Bombus per meter of transect in a given patch; Apis the mean density of A. mellifera / $\mathrm{m}$ across all observations in the previous year; Scal and Pmal the density of Scrophularia californica and Phacelia malvifolia flowers $/ \mathrm{m}$ of transect in the patch, respectively; and preciptime the precipitation timing (phenology) variable (Appendix I, Tab. S4). The model includes positive effects of $P$. malvifolia on Bombus abundance, and at higher $A$. mellifera densities also of $S$. californica (positive Apis x Scal interaction). In this model, greater numbers of $A$. mellifera in the previous year and later spring rainfall (precipitation timing) negatively affect Bombus abundances.

This original Bombus abundance model was fit using linear mixed effects regression and AIC-based model selection (Thomson 2016). I re-estimated model coefficients, to correct for several small errors in the 2000-20I4 data for floral abundances. These updates did not change the best-fit model structure and had minimal effects on coefficients (Appendix I, Tab. S4). Two of the four predictor variables reached values during 2015-2018 outside the range of 19992014 data used in model development. First, the abundance of P. malvifolia for one patch in 2018 fell 7.5 standard deviations away from the mean for the full 1999-2018 data set (see above). To avoid extrapolating predictions so far beyond the range used for fitting the original Bombus model, I removed this value from the analysis. Second, mean Apis density in the previous year reached values up to 1.27 times higher than the maximum observed from I999-2014 (Fig. I). These years were retained in the analyses (see Discussion).

I generated predicted values from the Bombus abundance model and compared them with observed values using Spearman's rank correlations, for three test data sets: (a) records for patches not included in the original model fitting but collected during the same time period (spatially novel; pre20I5, 3 patches, $N=12$ patch/year combinations); (b) records from 2015-2018 for the same patches used to fit the Bombus model (temporally novel; 9 patches, 26 patch/year combinations), and (c) all 2015-2018 data, including new patches (both spatially and temporally novel; I4 patches, 39 patch/year combinations). I quantified bias in model predictions as the mean and standard error of residuals; standard error bounds overlapping with zero support that predictions are unbiased. Predictions of the previously published model for $A$. mellifera abundance were not compared to observed values for 2015-2018, because the most recent four years of data clearly did not follow the same temporal trends as 1999-20I4 (see Discussion).

\section{RESULTS}

Both A. mellifera and Bombus abundances fluctuated substantially in the new period of data collection (Fig. I). Mean A. mellifera densities changed little in 2015 relative to the previous two years, but fell sharply by $58 \%$ in 2016 and then returned to higher levels similar to 2012-2014. Bombus densities remained low in 2015-2016 (mean: 0.027
Pollinator $\rightarrow$ Apis $\_$Bombus

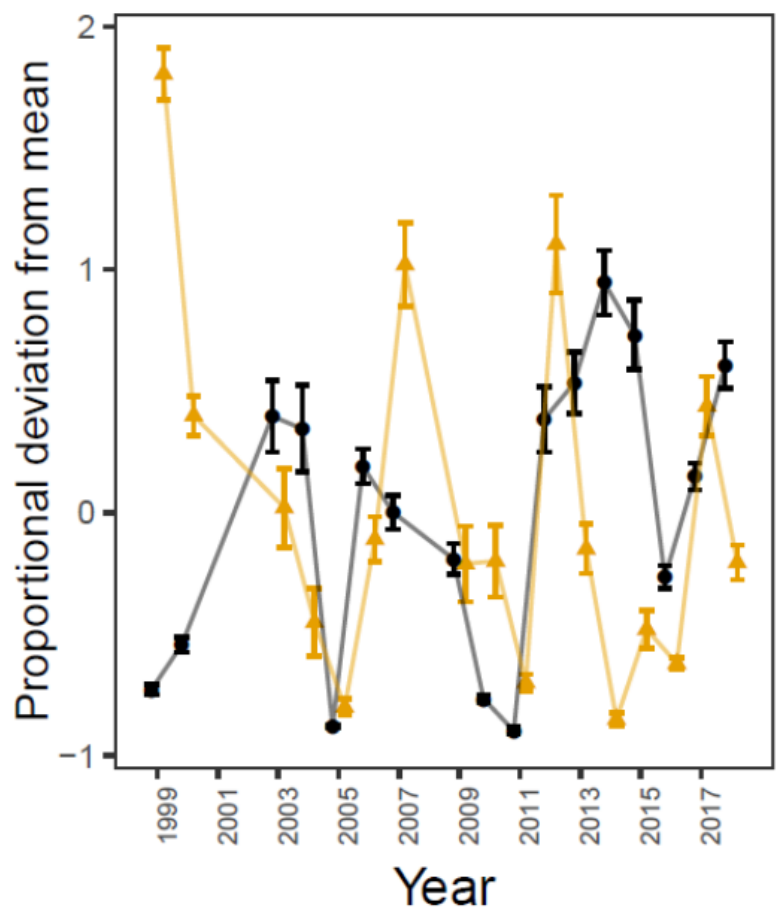

FIGURE I. Variation in annual Apis mellifera (triangles, orange line) and Bombus spp. (circles, black line) forager density/m transect (patch) surveyed, represented as proportional deviations from their means over the entire 1999-2018 monitoring period. Points and error bars show means across all patches monitored in each year \pm one standard error of the mean, respectively.

foragers $/ \mathrm{m}$ ), then rebounded by 3.8 times in 2017 before dropping again slightly in 2018.

In the new, best-fit models for drivers of floral abundance (hypothesis I), rainfall effects did not interact with time period of data collection for any plant species $(\Delta \mathrm{AIC}=-\mathrm{I} .82$ for Scrophularia californica, $\Delta$ AIC $=-\mathrm{I} .52$ for Stachys bullata, $\Delta$ AIC $=-1.96$ for E. staechadifolium; Appendix I, Tab. S3). More days of spring rain corresponded with higher floral abundances of key forage plants across all years (20002018), ranging from a very strong response for Scrophularia californica to a marginal one by Stachys bullata (Tab. I; Appendix 2, Fig. SI). Days of spring rain replaced total growing season precipitation as the most explanatory weather variable for E. staechadifolium. Scrophularia californica was less abundant in 2015-2018 than in 2000-2014, regardless of rainfall. Eriophyllum staechadifolium showed a decline similar to but much weaker than the one for $S$. californica. Later phenology decreased E. staechadifolium abundance at the time of annual monitoring, but increased Stachys bullata, and to a lesser degree also increased Scrophularia californica.

Across both time periods (1999-2018), higher $A$. mellifera density corresponded to reduced niche overlap with Bombus (hypothesis 2; Fig. 2A, Tab. 2). Greater A. mellifera density in the previous year strongly predicted lower mean Bombus density (hypothesis 3; Fig. 2B, Tab. 2). Bombus preference for foraging on E. staechadifolium went down in 
TABLE I. Results of mixed effects models evaluating how numbers of open flowers for three key forage plants responded to rainfall and precipitation timing (phenology), both in the 2000-2014 data originally used to develop predictive models and in 2015-2018. The precipitation timing (phenology) measure was calculated as the mean daily rainfall weighted by day in year, for Jan. I to July I; higher values indicate more rainfall happened later in spring. Rainfall did not interact with time period for any plant species $(\Delta$ AIC $=-1.82$ for Scrophularia californica, $\Delta$ AIC $=-I .52$ for Stachys bullata, $\Delta$ AIC $=-1.96$ for Eriophyllum staechadifolium).

\begin{tabular}{|c|c|c|c|c|c|c|c|}
\hline Forage plant & Factor & Estimate & $\mathrm{SE}$ & $t$ & $d f$ & $P$ & $\begin{array}{l}\Delta \\
\text { AIC }\end{array}$ \\
\hline \multirow[t]{3}{*}{ Scrophularia californica } & Days spring rainfall & 0.010 & 0.003 & 2.76 & 106.62 & 0.007 & 5.67 \\
\hline & Precipitation timing & 0.010 & 0.01 & 1.92 & 103.87 & 0.056 & 1.66 \\
\hline & Time (2015-20I8) & -0.125 & 0.04 & -3.05 & I I3.94 & 0.003 & 7.02 \\
\hline \multirow[t]{3}{*}{ Stachys bullata } & Days spring rainfall & 0.003 & 0.002 & 1.80 & I I 0.79 & 0.075 & 1.32 \\
\hline & Precipitation timing & 0.008 & 0.002 & 3.25 & $\mathrm{I} 07.85$ & 0.002 & 8.42 \\
\hline & Time (2015-2018) & -0.007 & 0.02 & -0.37 & II 6.93 & 0.72 & -1.88 \\
\hline \multirow[t]{3}{*}{ Eriophyllum staechadifolium } & Days spring rainfall & 0.022 & 0.01 & 2.16 & I06.02 & 0.033 & 2.72 \\
\hline & Precipitation timing & -0.052 & $0.0 \mathrm{I}$ & -3.47 & I04.82 & 0.0008 & 9.65 \\
\hline & Time (2015-2018) & $-0.24 \mathrm{I}$ & 0.12 & -2.01 & I 10.28 & 0.047 & 1.86 \\
\hline
\end{tabular}

Time • 1999-2014 A 2015-2018
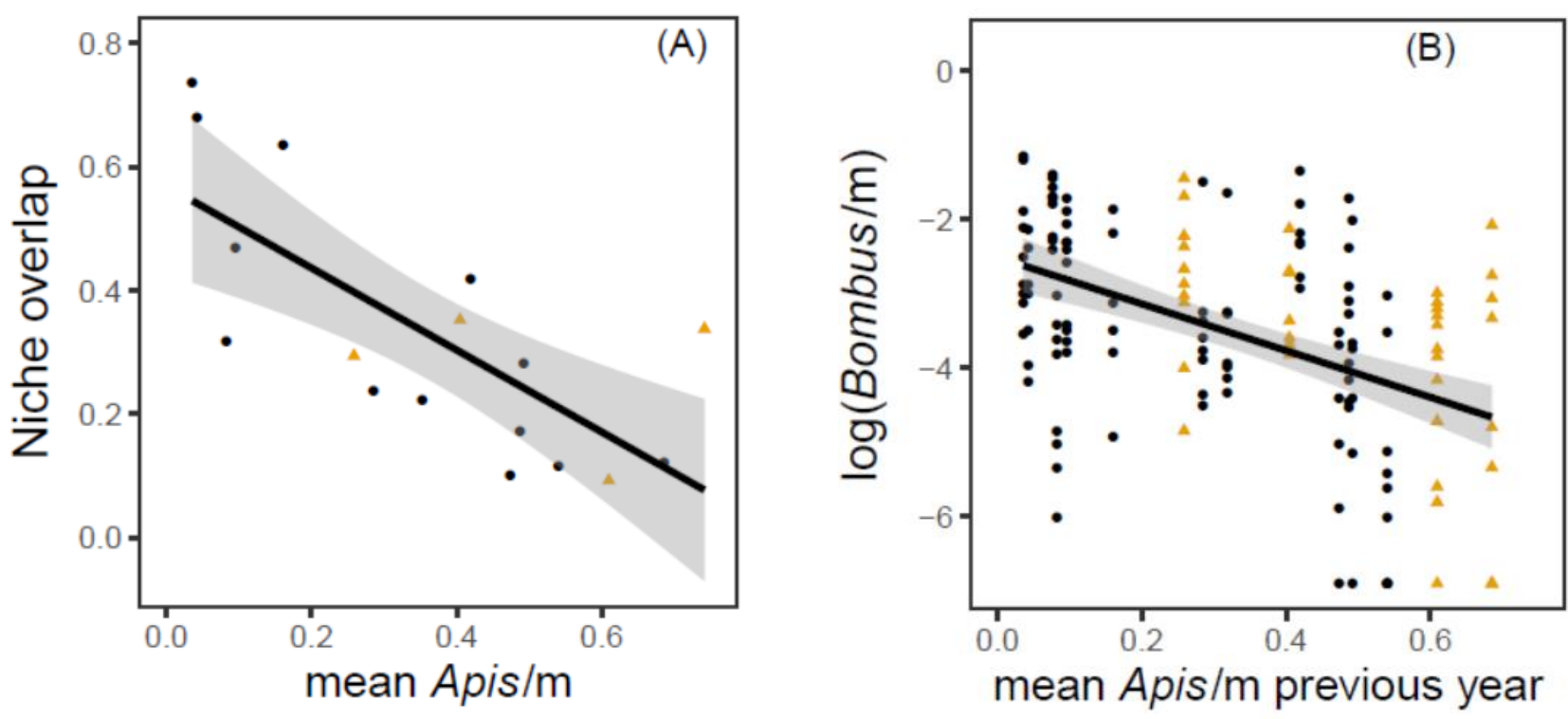

FIGURE 2. Relationships between (A) Apis mellifera forager density/m of transect and niche overlap with Bombus in the same year, and (B) A. mellifera forager density $/ \mathrm{m}$ in the previous year and log-transformed Bombus density $/ \mathrm{m}$ transect. Points represent years (means for A. mellifera density) in panel (A), and individual patches in panel (B). Black circles: 1999-20I4, orange triangles: 2015-2018. Lines and gray shading show bestfit regression predictions and 95\% confidence bounds, respectively, for the full 1999-2018 data set.

years with higher $A$. mellifera density (hypothesis $2 ; t=-2.25$, $d f=15, P=0.04, r=-0.50$; Appendix 2, Fig. S2A). Reductions in Bombus use of E. staechadifolium correlated marginally with lower niche overlap (hypothesis $2 ; t=2.07$, $d f=15, P=0.056, r=0.47$; Appendix 2, Fig. S2B). Niche overlap strongly, positively associated with Bombus density in the following year (hypothesis $3 ; t=3.26, d f=12, P=$ $0.007, r=0.69$; Appendix 2, Fig. S3). Dynamics in 2015-
2018 followed the same general patterns as in 2000-2014 (Appendix 2, Fig. S2, Fig. S3). When A. mellifera abundances dropped in 2016-17, Bombus preference for E. staechadifolium went up from very low levels $(2015=0.0 \mathrm{I})$ to moderately high levels $(2016=0.4 \mathrm{I}, 2017=0.34)$. Niche overlap likewise increased, from a range of 0.09-0.12 across the three previous years (20I3-20I5) to 0.29-0.35 in 2016- 
TABLE 2. Results of linear fixed (Niche overlap) and mixed effects (Bombus density) models testing the relationships between mean $A$. mellifera/ $\mathrm{m}$ and: (top) niche overlap with Bombus in the same year, (bottom) log-transformed Bombus foragers $/ \mathrm{m}$ in the following year.

\begin{tabular}{lllllll}
\hline Response & Factor & Estimate & SE & $t$ & $d f$ & $P$ \\
\hline Niche overlap & Mean Apis $/ \mathrm{m}$ & -0.84 & 0.18 & -4.67 & $\mathrm{I}$ & 0.0004 \\
& Time period (2015-2018) & -0.28 & $0.2 \mathrm{I}$ & -1.37 & $\mathrm{I}$ & 0.19 \\
& Time period x Apis/m & 0.72 & $0.4 \mathrm{I}$ & $\mathrm{I} .77$ & $\mathrm{I}$ & 0.10 \\
$\log ($ Bombus $/ \mathrm{m})$ & Apis/m previous year & -3.57 & 0.64 & -5.60 & $\mathrm{I} 29.36$ & $<0.000 \mathrm{I}$ \\
& Time period (2015-2018) & 0.82 & 0.65 & $\mathrm{I} .25$ & $\mathrm{I} 37.70$ & $0.2 \mathrm{I}$ \\
& Time period x Apis/m & -0.73 & 1.33 & -0.54 & $\mathrm{I} 32.27$ & 0.58 \\
\hline
\end{tabular}

2017. However, niche overlap remained at 0.34 in 2018 even as $A$. mellifera abundances increased.

Predictions from the fixed effects Bombus abundance model correlated strongly with observed densities for the I999-20I4 patch data not used in model fitting (spatially novel; hypothesis 4a; rho $=0.87, P<0.001$; Appendix 2, Fig $\mathrm{S} 4$ ). These predictions were relatively unbiased (mean $\pm \mathrm{SE}$ of residuals $=0.18 \pm 0.30)$. Model predictions likewise correlated with the 2015-2018 observations (both spatially and temporally novel; hypothesis $4 \mathrm{c}$; rho $=0.59, P<0.001$; Fig. 3A), particularly for patches included in the original model fitting (only temporally novel; hypothesis $4 \mathrm{~b}$; rho $=$ 0.69, $P<0.00 \mathrm{I})$. However, the model underpredicted observed Bombus densities in 2015-2018, showing evidence of bias (mean \pm SE of residuals: all 1999-20I4 patches $=$ $0.86 \pm 0.20$, I999-20I4 patches included in model fitting $=$ $0.55 \pm 0.26)$.

I carried out a post-hoc analysis to assess potential sources of bias in model predictions. Individual years varied substantially in residual variation, with differences in flowering or Bombus phenology one potential explanation (Fig. 3A, Fig. 4A). The original model used a measure of precipitation timing to control for phenological variation among years (see Methods). Between 2015 and 2018 this relationship between precipitation timing and floral phenology was much weaker, and the slope differed (time period by precipitation timing interaction, $t=6.6, d f=6, P$ $<0.00$ I; Appendix 2, Fig. S5).

I calculated corrected values for the precipitation timing (phenology) predictor in 2015-2018 from a regression of the 2009-20I4 data, effectively putting 2015-2018 data on the same phenology scale used in fitting the original model. This correction slightly improved correlations between predicted and observed ( $r$ ho $=0.64$ for all patches, $r$ tho $=0.79$ for those included in model fitting; Fig. 3B). Bias also went down, although the model still consistently underpredicted Bombus abundances for patches not included in the original fitting (mean \pm SE of residuals: all patches $=0.48 \pm 0.18$, included patches $=0.19 \pm 0.22$; Fig. 3B). For all patches across the full data set (1999-2018), individual years likewise tended to show bias towards model over or under prediction (Fig. 4).

\section{DISCUSSION}

Challenging models with novel data is an important way to evaluate whether they capture key causal mechanisms and not just correlations. Assessing model transferability also helps define the limits of extrapolation, both spatially and temporally. The analyses presented here show that a simple model based on abundance of key forage plants and density of a non-native competitor can qualitatively predict observations from new years (temporally novel) and, on a local scale, also new flower patches (spatially novel). The findings further strengthen evidence that floral resources are an important driver of Bombus abundances, and that in California coastal scrub rainfall and competition with Apis mellifera mediate resource availability.

All three hypotheses about the mechanistic links between floral resources and Bombus abundance trends were supported by these new analyses. First, precipitation (days of spring rainfall) predicted floral abundance for all three forage plants across both time periods, but most strongly for a species preferred by Bombus (Scrophularia californica) (hypothesis I; Tab. I). Interestingly Scrophularia californica and to some extent also E. staechadifolium flower numbers were lower in 2015-2018 regardless of spring rain (Tab. 2). Both perennial and annual plant communities across California show persistent negative effects of the 20II-2016 drought, even since the well above-average rain year of 2016-2017 (Harrison et al. 2018; Okin et al. 2018). Over the last decade, bee forage plants in some study patches have been replaced by highly drought-tolerant species such as Baccharis pilularis ssp. consanguinea and Toxicodendron diversilobium (Kidder 20I5). These patterns support both within-year and longterm negative effects of drought on floral resources that in turn reduce Bombus abundances.

The new findings presented here also strengthen support for a key role of competition with A. mellifera in Bombus declines at this site, particularly competition for the most abundant floral resource (E. staechadifolium). As predicted (hypothesis 2), higher A. mellifera densities reduced Bombus preference for E. staechadifolium and decreased niche overlap, as would be expected when competition intensifies. In turn, lower niche overlap corresponded with lower Bombus abundance in the following year (hypothesis 3 ). These 

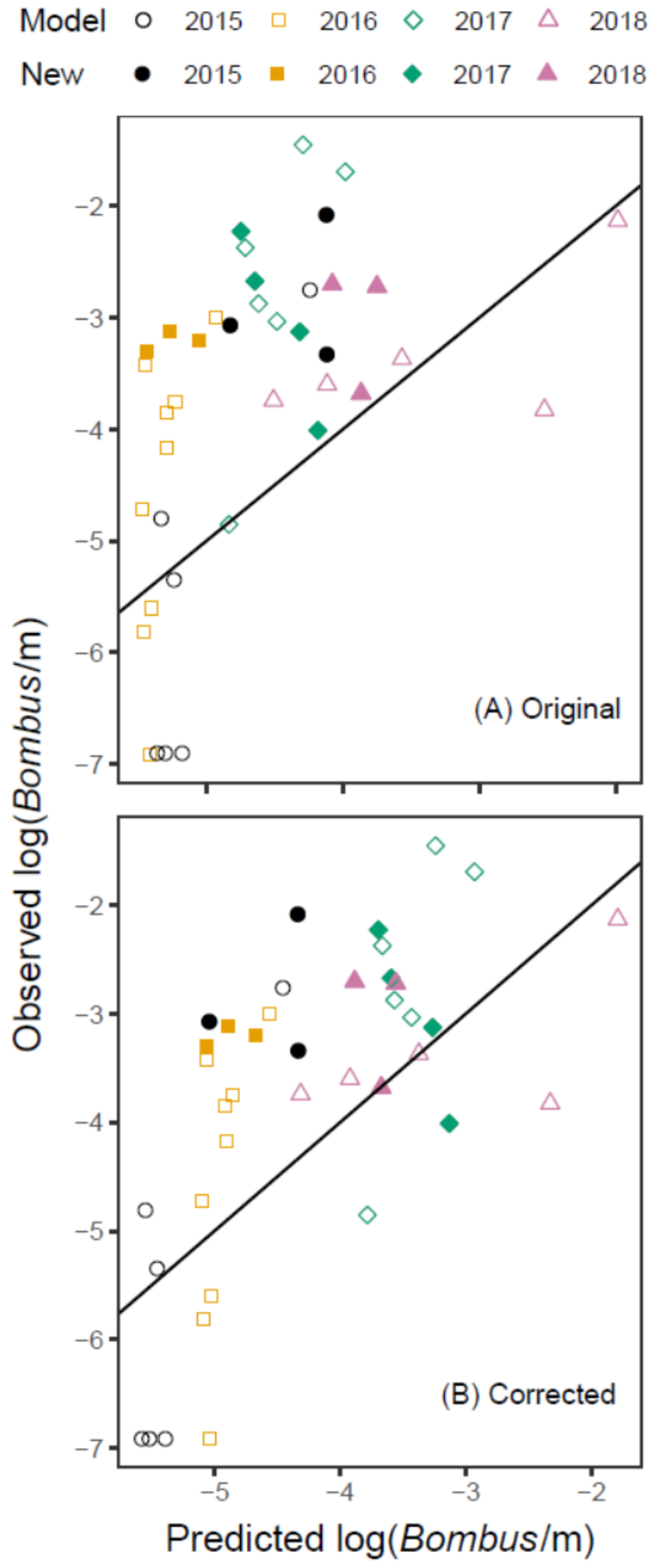

FIGURE 3. Relationships between the independently predicted and observed Bombus forager density/m transect in 2015-2018, for predictions made using either the $(A)$ original or $(B)$ corrected values of the precipitation timing (phenology) fixed effect variable. Both predicted and observed values are shown on the same log scale used to fit the original model with data from 1999-2014. Lines show where a I:I relationship would fall. Each point represents a single patch within a given year; open symbols are patches included in the original model fitting, and closed symbols new patches independent of the model fitting. patterns are consistent with the explanation that at higher abundances $A$. mellifera largely exclude Bombus from foraging on E. staechadifolium, reducing Bombus reproductive success and therefore population numbers in the next year. Eriophyllum staechadifolium flowering lags other key forage plants, constituting on average $49 \%$ of inflorescences with open flowers during the monitoring window but over $70 \%$ by the end of the flight season (I999: 43.1\% monitoring window, $74.2 \%$ August; 2000: 64.7\% monitoring window, 82.1\% August). In parallel, niche overlap with A. mellifera intensifies later in the Bombus flight season as the diversity and abundance of floral resources declines (Thomson 2006). Late season floral resources may be particularly important to queen production in bumble bee colonies (Rundlöf et al. 20I4; Thomson \& Page 2020). For example, availability of late-flowering Brassica crops correlated with greater Bombus colony reproduction in a European agricultural landscape (Hass et al. 2019). Loss of late-season resources has also been connected to increased extinction risk for British bees (Balfour et al. 2018).

Reduced access to the aster E. staechadifolium potentially affects the amount, diversity, and nutritional characteristics of collected pollen, all associated with Bombus colony development and reproductive success (Thomson \& Page 2020). Intriguing recent research suggests that aster pollen may benefit bumble bee health by altering microbiome composition and promoting parasite resistance (Giacomini et al. 2018; LoCascio et al. 2019; Fowler et al. 2020). Nutritional status and pathogen load in newly emerged queens could affect overwinter survival and nest establishment success in the following spring (Woodard et al. 2019).

Apparent competition due to parasite or disease transmission from A. mellifera into Bombus populations is an important alternative hypothesis for negative correlations between their abundances (Fürst et al. 20I4). Disappearance of the once widespread B. occidentalis along the Pacific coast of North America has been linked with introduction of the fungal pathogen Nosema bombii, but occurred before this study began in 1999 (Cameron et al. 2016). Further, apparent competition does not explain why reduced sharing of floral resources correlates so strongly with Bombus declines. Increased niche partitioning seems likely if anything to reduce the frequency of interspecific disease transmission at flowers (Adler et al. 202I).

The fixed effects model developed for Bombus abundances from I999-20I4 also proved effective for qualitatively predicting new observations (hypothesis 4). As the goal of modelling in this case was to identify key drivers rather than precisely predict future dynamics, this result is encouraging. Still, limitations identified in model validation can help illuminate potential gaps in our mechanistic understanding of drivers. The model performed best for new patches observed over the same time period used in model fitting (spatially novel; rho $=0.89$; Appendix SI, Fig. S4). These patches were all within $100 \mathrm{~m}$ of those used in fitting the original model, well within the foraging range of both $A$. mellifera and Bombus. Most studies on spatial transferability of ecological models involve much larger distances, for example in predicting species distributions. At the same time, 


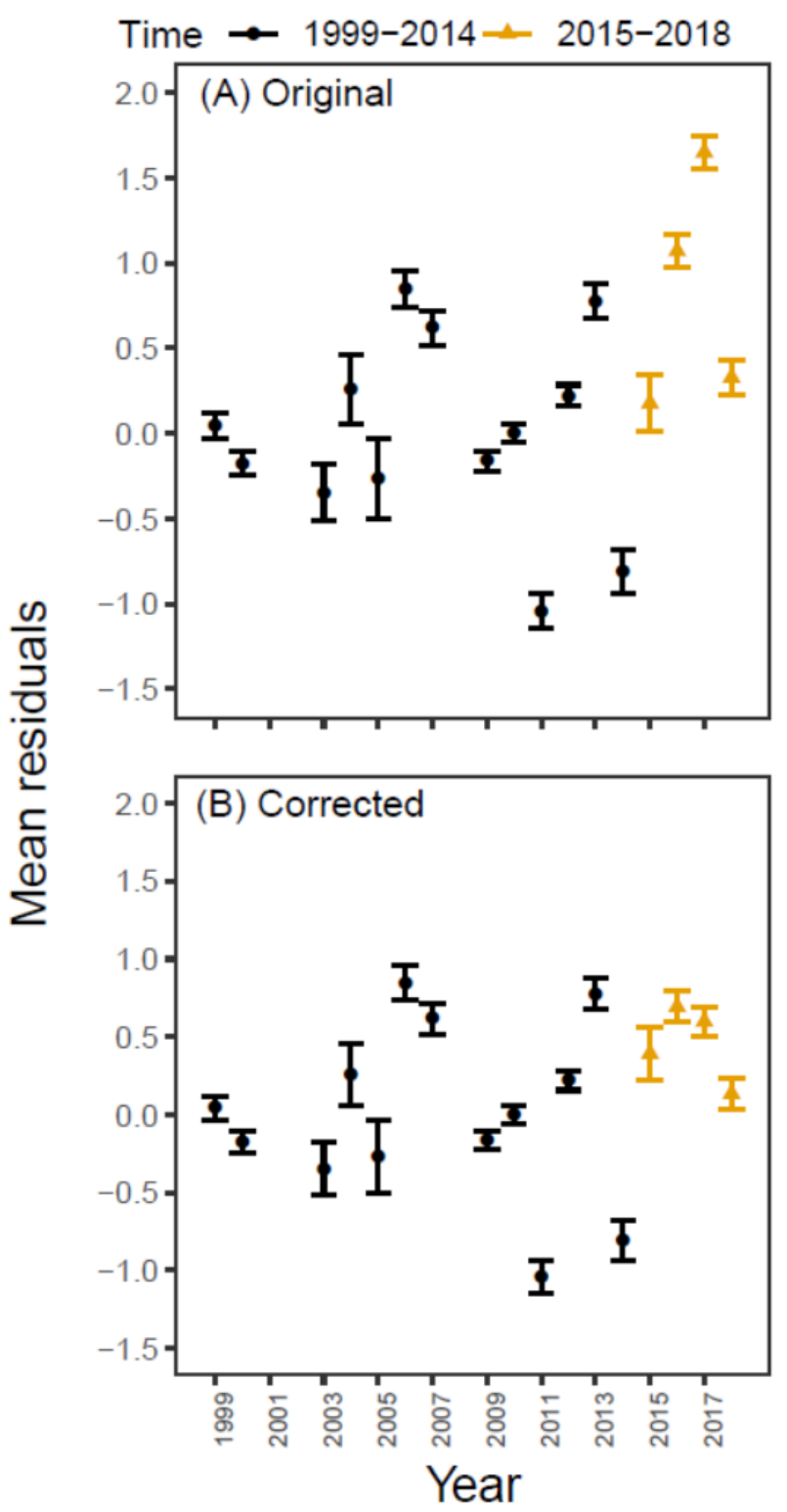

FigURE 4. Mean \pm one standard error of the mean for model residuals across all patches monitored in each year, for predictions made using either the (A) original or (B) corrected values for the precipitation timing (phenology) fixed effect variable in 2015-2018. Black circles show years used in model development, and orange triangles new years used to evaluate the model.

environmental similarity rather than distance per se appears to determine how well models extrapolate spatially (Yates et al. 2018). The Bombus abundance model also performed well when predicting new years for the same patches used in the original model fitting, after correcting the precipitation timing variable (temporally novel; tho $=0.79$ ). This finding is notable given that the predictions required extrapolating beyond the range of $A$. mellifera densities used to develop the original model (see Methods, Fig. I).

However, including new patches in the 2015-2018 data (hypothesis $4 \mathrm{c}$, both spatially and temporally novel) led to bias, with underestimation of Bombus abundances. This may reflect that the two completely new patches added from 20152018 were slightly further away (I50 m and I km). The density of nesting sites and colonies within close foraging range of these patches might have differed as a result, changing the relationships between floral abundances and bee abundance. Corrected residuals for these two patches alone averaged $1.28 \pm 0.48(N=5)$. However, it is also possible that non-random patch selection promoted bias in predictions. The two completely new patches were deliberately chosen from areas that still support substantial numbers of the primary bee forage plants. In contrast, most patches sampled from 1999-20I4 were established early in the study before drought-related declines in floral abundance began (Thomson 2016). These two potential explanations lead to different conclusions about the limits of extrapolation for the Bombus abundance model. If expanding the spatial scale of the plots rather than non-random patch selection led to bias, adding predictors that capture landscape variation may be necessary to make the model more generalizable.

Across both time periods, most of the imprecision in estimates of Bombus abundance was related to variation between years, rather than variation among patches within years (Fig. 4). This difference may reflect that foraging behaviour and patch selection likely drive most within-year variation, while between-year variation is strongly influenced by population change. A myriad of abiotic and biotic factors potentially influences Bombus populations (Jha \& Kremen 2013; Crone \& Williams 2016), so it is unsurprising that a model including few independent variables did not fully predict abundance dynamics. At the same time, simpler models, or those with a few major predictors, often outperform more complex models when challenged with outof-sample data (Wenger \& Olden 2012; Oliver \& Roy 2015; Clark et al. 2020).

Feral $A$. mellifera numbers also showed high interannual variability, with the causes as yet unclear (Fig. I). In the late I990s, spread of Varroa destructor led to major losses of feral A. mellifera colonies in the central valley of California (Kraus \& Page 1995). Estimating population sizes for feral $A$. mellifera is very difficult (Utaipanon et al. 2019), and few studies assess whether they respond to parasites in the same way as domesticated colonies (Thompson et al. 20I4). Still, a handful of studies document $A$. mellifera populations apparently resistant to $V$. destructor (Seeley 2007; Locke 2016). Feral $A$. mellifera also have been shown to dominate foraging in other southern California coastal locations (Hung et al. 2019). My findings here suggest that a better understanding of how much and why feral $A$. mellifera numbers fluctuate may be key to conservation planning for Bombus in California coastal scrub.

This study adds to growing evidence that sustaining floral resources is critical to bee populations, and reinforces that both drought and competition from Apis mellifera are reducing Bombus access to such resources in California coastal scrub. These findings also demonstrate the value of simple, mechanistically-framed models, not only in understanding past patterns of change but for qualitatively predicting spatially and temporally novel data. Analyses that document trends in pollinator abundances play an important part in the emerging picture of pollinator declines, but trends can change for reasons that may be unclear (Thomson 2019). Models based on potential drivers of population dynamics can help us 
test hypotheses about the underlying causes of change and develop better predictions and management strategies.

\section{ACKNOWLEDGEMENTS}

Data collection was supported from 1999-2000 by National Science Foundation grant DEB-99-02269, and since 2004 by the W.M. Keck Science Department. I thank the University of California Natural Reserve System and M. Readdie and F. Arias of the LandelsHill Big Creek Reserve for field support. I deeply appreciate the many thoughtful suggestions of two reviewers and the editor.

\section{APPENDICES}

Additional supporting information may be found in the online version of this article:

APPENDIX I. Supporting Tables.

APPENDIX II. Supporting Figures.

\section{REFERENCES}

Adler LS, Irwin RE, McArt SH, Vannette RL (202I) Floral traits affecting the transmission of beneficial and pathogenic pollinatorassociated microbes. Current Opinion in Insect Science 44:I-7.

Balfour NJ, Ollerton J, Castellanos MC, Ratnieks FLW (2018) British phenological records indicate high diversity and extinction rates among late-summer-flying pollinators. Biological Conservation 222:278-283.

Bartomeus I, Stavert JR, Ward D, Aguado O (2019) Historical collections as a tool for assessing the global pollination crisis. Philosophical Transactions of the Royal Society B: Biological Sciences 374:I-9.

Bates D, Machler M, Bolker B, Walker S (2015) Fitting linear mixed-effects models using lme4. Journal of Statistical Software 67:I-48.

Cameron SA, Lim HC, Lozier JD, Duennes MA, Thorp R (2016) Test of the invasive pathogen hypothesis of bumble bee decline in North America. Proceedings of the National Academy of Sciences of the United States of America II3:4386-439I.

Clark AT, Turnbull LA, Tredennick A, Allan E, Harpole WS, Mayfield MM, Soliveres S, Barry K, Eisenhauer N, de Kroon H, Rosenbaum B, Wagg C, Weigelt A, Feng Y, Roscher C, Schmid B (2020) Predicting species abundances in a grassland biodiversity experiment: Trade-offs between model complexity and generality. Journal of Ecology I08:774-787.

Crone EE, Williams NM (2016) Bumble bee colony dynamics: Quantifying the importance of land use and floral resources for colony growth and queen production. Ecology Letters 19:460468.

Fowler AE, Stone EC, Irwin RE, Adler LS (2020) Sunflower pollen reduces a gut pathogen in worker and queen but not male bumble bees. Ecological Entomology 45:1318-1326.

Fürst MA, McMahon DP, Osborne JL, Paxton RJ, Brown MJF (2014) Disease associations between honeybees and bumblebees as a threat to wild pollinators. Nature 506:364-366.

Giacomini JJ, Leslie J, Tarpy DR, Palmer-Young EC, Irwin RE, Adler LS (2018) Medicinal value of sunflower pollen against bee pathogens. Scientific Reports 8:I-I0.

Goulson D, Nicholls E, Botías C, Rotheray EL (2015) Bee declines driven by combined stress from parasites, pesticides, and lack of flowers. Science 347:1255957.

Harrison SP, LaForgia ML, Latimer AM (2018) Climate-driven diversity change in annual grasslands: Drought plus deluge does not equal normal. Global Change Biology 24:1782-1792.
Hass AL, Brachmann L, Batáry P, Clough Y, Behling H, Tscharntke T (2019) Maize-dominated landscapes reduce bumblebee colony growth through pollen diversity loss. Journal of Applied Ecology 56:294-304.

Houlahan JE, McKinney ST, Anderson TM, McGill BJ (2017) The priority of prediction in ecological understanding. Oikos I26:I-7.

Hung KLJ, Kingston JM, Lee A, Holway DA, Kohn JR (2019) Non-native honey bees disproportionately dominate the most abundant floral resources in a biodiversity hotspot. Proceedings of the Royal Society B: Biological Sciences 286:2018290I

Jha S, Kremen C (2013) Resource diversity and landscape-level homogeneity drive native bee foraging. Proceedings of the National Academy of Sciences II0:555-558.

Kidder AG (2015) On Baccharis pilularis DC. (coyote brush, Asteraceae) Water Relations During Succession Into Coastal Grasslands in a Changing Climate. University of California, Berkeley.

Kraus FB, Page RE (1995) Effect of Vartoa jacobsoni (Mesostigmata: Varroidae) on feral Apis mellifera (Hymenoptera: Apidae) in California. Environmental Entomology 24:1473-I480.

Kuznetsova A, Brockhoff PB, Christensen RHB (2017) lmerTest Package: Tests in Linear Mixed Effects Models. Journal of Statistical Software 82:30567.

LoCascio GM, Aguirre L, Irwin RE, Adler LS (2019) Pollen from multiple sunflower cultivars and species reduces a common bumblebee gut pathogen. Royal Society Open Science 6: 190279

Locke B (2016) Natural Vartoa mite-surviving Apis mellifera honeybee populations. Apidologie 47:467-482.

Luke SG (2017) Evaluating significance in linear mixed-effects models in R. Behavior Research Methods 49:1494-1502.

Mouquet N, Lagadeuc Y, Devictor V, Doyen L, Duputié A, Eveillard D, Faure D, Garnier E, Gimenez O, Huneman P, Jabot F, Jarne P, Joly D, Julliard R, Kéfi S, Kergoat GJ, Lavorel S, Le Gall L, Meslin L, Morand S, Morin X, Morlon H, Pinay G, Pradel R, Schurr FM, Thuiller W, Loreau M (2015) Predictive ecology in a changing world. Journal of Applied Ecology 52:I293-I3I0.

Ogilvie JE, Griffin SR, Gezon ZJ, Inouye BD, Underwood N, Inouye DW, Irwin RE (2017) Interannual bumble bee abundance is driven by indirect climate effects on floral resource phenology. Ecology Letters 20:1507-I5I5.

Okin GS, Dong C, Willis KS, Gillespie TW, MacDonald GM (2018) The impact of drought on native southern California vegetation: Remote sensing analysis using MODIS-derived time series. Journal of Geophysical Research: Biogeosciences I23:1927_ 1939.

Oliver TH, Roy DB (2015) The pitfalls of ecological forecasting. Biological Journal of the Linnean Society I I5:767-778.

Powney GD, Carvell C, Edwards M, Morris RKA, Roy HE, Woodcock BA, Isaac NJB (2019) Widespread losses of pollinating insects in Britain. Nature Communications I0:I-6.

Rundlöf M, Persson AS, Smith HG, Bommarco R (20I4) Lateseason mass-flowering red clover increases bumble bee queen and male densities. Biological Conservation I72:138-I45.

Sánchez-Bayo F, Wyckhuys KAG (2019) Worldwide decline of the entomofauna: A review of its drivers. Biological Conservation 232:8-27.

Seeley TD (2007) Honey bees of the Arnot Forest: A population of feral colonies persisting with Varroa destructor in the northeastern United States. Apidologie 38:19-29.

Soroye P, Newbold T, Kerr J (2020) Climate change contributes to widespread declines among bumble bees across continents. Science 367:685-688. 
Thompson CE, Biesmeijer JC, Allnutt TR, Pietravalle S, Budge GE (20I4) Parasite pressures on feral honey bees (Apis mellifera sp.). PLoS ONE 9:I-8.

Thomson DM (2006) Detecting the effects of introduced species: A case study of competition between Apis and Bombus. Oikos II $4: 407-4$ I8

Thomson DM (2016) Local bumble bee decline linked to recovery of honey bees, drought effects on floral resources. Ecology Letters I9:1247-I255.

Thomson JD (2019) Progressive deterioration of pollination service detected in a 17-year study vanishes in a 26-year study. New Phytologist 224:I I5I-II59.

Thomson DM, Page ML (2020) The importance of competition between insect pollinators in the Anthropocene. Current Opinion in Insect Science 38:55-62.

Utaipanon P, Schaerf TM, Oldroyd BP (2019) Assessing the density of honey bee colonies at ecosystem scales. Ecological Entomology 44:29I-304.
Wenger SJ, Olden JD (2012) Assessing transferability of ecological models: An underappreciated aspect of statistical validation. Methods in Ecology and Evolution 3:260-267.

Woodard SH, Duennes MA, Watrous KM, Jha S (2019) Diet and nutritional status during early adult life have immediate and persistent effects on queen bumble bees. Conservation Physiology 7:I-I0.

Yates KL, Bouchet PJ, Caley MJ, Mengersen K, Randin CF, Parnell S, Fielding AH, Bamford AJ, Ban S, Barbosa AM, Dormann CF, Elith J, Embling CB, Ervin GN, Fisher R, Gould S, Graf RF, Gregr EJ, Halpin PN, Heikkinen RK, Heinänen S, Jones AR, Krishnakumar PK, Lauria V, Lozano-Montes H, Mannocci L, Mellin C, Mesgaran MB, Moreno-Amat E, Mormede S, Novaczek E, Oppel S, Ortuño Crespo G, Peterson AT, Rapacciuolo G Roberts JJ, Ross RE, Scales KL, Schoeman D, Snelgrove P, Sundblad G, Thuiller W, Torres LG, Verbruggen H, Wang L, Wenger S, Whittingham MJ, Zharikov Y, Zurell D, Sequeira AMM (2018) Outstanding challenges in the transferability of ecological models. Trends in Ecology and Evolution 33:790-802. 